\title{
MEMÓRIAS, EXPERIÊNCIAS E POLÍTICA: PRIMEIROS ESCRITOS À "CONTRAPELO" DA HISTÓRIA DO CLUBE DO BARRIL (1975 - 2015)
}

\author{
Josiane Eugênio Pereira ${ }^{1}$ \\ Cássia Cilene de Almeida Chalá Machado²
}

\section{INTRODUÇÃO}

Compreendendo que as rememorações influenciam no modo de ser, estar e perceber o mundo, teceremos neste trabalho os fios das memórias de professores e funcionários do Colégio de Aplicação da Universidade Federal de Santa Catarina (UFSC) que se associaram ao Clube do Barril, procurando identificar até que ponto essas memórias e experiências foram trazidas para dentro do exercício das suas profissões. Cabe salientar, que a memória nunca é somente a do sujeito isolado, mas de um individuo inserido em um contexto social, familiar, religioso, cultural, etc. Desta forma, ao refletirmos sobre o Clube do Barril, perguntamo-nos sobre qual a concepção de sujeito aqui adotada: Quem é o sujeito que viveu essa experiência? Em quais espaços eles intercambiaram suas experiências? Que relações sociais são estabelecidas no contexto estudado?

Percebendo que o passado ajuda de certa forma a entender o tempo presente, esse artigo acaba se tornando um instrumento confessional das memórias, das narrativas e experiências, tornando-se um instrumento autoavaliativo, visto que, se constitui num repensar do passado e do presente como uma forma de reflexão e diálogo de um grupo de pessoas com elas mesmas e com as outras.

Num primeiro momento apresentamos a contextualização da pesquisa, a experiência enquanto acontecimento das particularidades do vivenciado, as relações e influências externas políticas nos encontros dos professores com professores, com outros funcionários, com a equipe pedagógica e técnica 'fora' dos espaços do Colégio de Aplicação da UFSC. No segundo momento, estabelecemos um breve

\footnotetext{
${ }^{1}$ Mestra em Educação - Professora da Educação Especial no Colégio de Aplicação/UFSC. E-mail: josiane.eugenio@ufsc.br

2 Mestranda em Educação na Universidade Federal de Santa Catarina. Professora da Educação Especial no Colégio de Aplicação/UFSC. E-mail: cássia.chala@ufsc.br
} 
reflexão teórica sobre a memória, a História Oral analisando os sentidos produzidos nas memórias dos sujeitos associados, que contam suas experiências enquanto sócios do Clube do Barril (1975-2015).

No que diz respeito ao tema deste estudo, as experiências vividas, as memórias do tempo do Barril constitui-se de uma fonte de pesquisa que necessita de uma metodologia e aqui abordada por meio da História Oral, supondo que a mesma 'ofereça voz' aos narradores. Para o conceito de narrador buscamos amparo em leituras benjaminianas. Ao embrenharmos por textos de Walter Benjamin (18921940), filósofo alemão, crítico, poeta e teórico especialmente da memória e da conservação do passado, os quais trouxeram subsídios para pensarmos no desenvolvimento da questão das rememorações de nossos narradores, entre o lembrar e o esquecer. Dizemos isso, já valendo-nos do sentido amplo da palavra narrador, que o autor emprega no sentido de 'contadores' em seus textos. Assim, começamos a costurar os fios das memórias de alguns sócios do Clube do Barril, aqui assinalando o seu pertencimento ao grupo.

\section{NARRATIVAS, MEMÓRIAS E EXPERIÊNCIAS DOS SÓCIOS DO CLUBE DO BARRIL}

Contextualizando a pesquisa e nossa intencionalidade enquanto pesquisadoras, situamos o espaço de investigação onde a pesquisa foi realizada no município de Florianópolis-SC, no Colégio de Aplicação da Universidade Federal de Santa Catarina (UFSC).

Embora exista no Colégio muitos materiais arquivados, documentos, jornais, fotografias, atas escolares, os álbuns de fotografias do Clube do Barril ainda não haviam sido explorados para estudo. Ao sermos levadas para conhecer 0 acervo do Colégio ficamos admiradas com a riqueza de detalhes que nos foi apresentado pela secretária, especialmente quanto ao acervo do 'Clube do Barril'. Eram tantos as proeminências, a disposição das fotografias nos antigos álbuns fotográficos, a Ata de fundação, a organização da Associação... $E$ isso não era limitada a função de secretária que a servidora exerce. Por exemplo, a Sr. Patrícia 
B. Orofino ${ }^{3}$ lembrava-se com certo saudosismo das festas, nomes dos colegas de profissão, das datas e da documentação do Clube. E mais tarde, soubemos que a mesma foi aluna do Colégio, antes mesmo de adentrar no quadro de funcionários. Havia sobretudo, um sentimento de pertencimento.

Nesse primeiro momento, com os documentos e com a servidora, a conversa oscilou entre a desconfiança da narradora em se convencer de que tinha informações 'úteis' a pesquisa e várias indicações de sócios que saberiam 'contar' mais sobre o Clube do Barril (informação verbal) 4 .

No intuito de explicitar o processo de construção da investigação, escolhemos pesquisar três professores (dois deles ocuparam o cargo de presidente do Clube, estando dois ativos e um aposentado) e um técnico administrativo (ativo).

Após o contato com os narradores indicados pela secretária para deixálos cientes das limitações deste estudo e informados sobre as ideias que permeavam a ideia da pesquisa, iniciamos os primeiros contatos a fim de buscar elementos singulares de cada membro, que embora particulares, por serem vidas distintas, em alguns momentos, uniam-se às histórias do(s) outro(s).

Lembrando que, é justamente no rastreamento das memórias, sensações e dos sabores que as rememorações ganham contornos a partir da narrativa de Patrícia que inicia a apresentação do Clube falando das festas realizadas na casa dos professores e funcionários, com churrasco, comida, bebida, carvão, salada, maionese...Que amanheciam muitas vezes, dançando, cantando, pois sentiam prazer em estar juntos e compartilhar as experiências de vida e profissionais. ${ }^{5}$

Cabe destacar, que a escola é um lugar onde há múltiplas possibilidades de experiências, pois a todo momento estamos interagindo com uma diversidade de situações e sujeitos (alunos, professores, gestão, funcionários, famílias, etc.), com suas particularidades, histórias de vida e singularidades, e cada uma dessas nos afeta de uma maneira diferente. No entanto, só há acontecimento como experiência, segundo Larosa (2003), se o professor se deixar afetar, e isso inclui, correr todos os 'perigos' a que está exposto.

\footnotetext{
${ }_{4}^{3}$ Patrícia Belo Orofino. Informações verbais.

4 Primeiro contato com a secretária e com o acervo do Colégio de Aplicação, em 28 de Maio de 2015.

${ }^{5}$ Patrícia Belo Orofino Pires. Técnica Administrativa, secretaria do Colégio de Aplicação. Entrevista concedida a Josiane Eugênio Pereira e Cássia Machado. Florianópolis.11/08/2015.
} 
Podemos perceber que muitas dessas experiências vividas, são esquecidas com o passar do tempo e apenas algumas continuam sendo recordadas, aquelas que talvez foram as mais 'significativas'. É interessante perceber que ao utilizar diferentes linguagens para expressar aquilo que nos marcou o pensamento, aquilo que aconteceu como experiência, por mais que tenha sido vivenciado por outros sujeitos, num espaço coletivo, jamais será narrado de maneira idêntica à de outra, por isso não há possibilidade de 'resgate' da memória pois para cada sujeito as experiências vividas possuem significados diversos.

Nesse cenário a História Oral apresentou-se como "Um método de pesquisa que utiliza a técnica da entrevista e outros procedimentos articulados entre si, no registro de narrativas de experiências humanas". (FREITAS, 2006, p. 18). Diferentemente das fontes escritas não prima por verdades absolutas e nem por exaltar a história oficial e sim, por fortalecer a fonte identitária do povo, retratando e valorizando suas realidades, vivências e modos de vida de cada um em cada tempo e momento.

Por meio do depoimento coletado, o pesquisador consegue compreender fatos históricos e empregar um outro tipo de fonte em suas pesquisas, que não se restringe aos documentos escritos que são comumente localizados em arquivos, museus, bibliotecas, escolas e outras instituições. ( OLIVEIRA, 2013,p.62).

\section{As memórias dos Sócios sobre a organização do Clube do Barril no contexto do Colégio de Aplicação UFSC}

No inicio da década de 1960 enquanto a Universidade era instituída para atender a demanda do ensino superior e profissionalização o Colégio de Aplicação, antigo Ginásio de Aplicação da Universidade Federal de Santa Catarina, criado um ano depois em 1961, tinha por objetivo funcionar como campo de estágio orientado e supervisionado para estudantes dos cursos de Licenciatura em diferentes áreas do conhecimento. A denominação Ginásio de Aplicação foi, ao longo do tempo, substituída à medida que esses colégios passaram a oferecer o curso Colegial/ Normal e, por último, os anos iniciais do ensino fundamental. $O$ ensino médio foi criado, apenas em 1969, num segundo ciclo (ANDRADE, 2009, p. 22). 
Na dissertação de Mestrado de Maria Clarete Borges de Andrade (2009), ao informar sobre o quadro permanente de professores do CA-UFSC no início de seu funcionamento, diz que este era constituído pelos professores do Departamento de Métodos de Ensino e por professores contratados pelo colégio, além de um corpo rotativo, composto por ex-alunos que depois de formados nos cursos de licenciatura, eram convidados a fazer um estágio de um ano no Colégio.

Assim, os professores e funcionários, sentiram a necessidade de se reunirem em outros locais, para além dos espaços da escola, para falarem de assuntos pessoais e fortalecer os vínculos de amizade. A partir desse interesse em comum, um grupo de pessoas: professores, ex-professores, técnicos administrativos e ex-funcionários, do Colégio organizaram-se na criação do Clube do Barril.

O professor Antônio F. Filho ${ }^{6}$ recorda que na Ata de criação do Clube (fundado aos dezoito dias do mês de setembro de 1975), já constava o objetivo maior que era o de integrar professores e funcionários do Colégio de Aplicação da UFSC. No primeiro momento do Clube (após a fundação, até meados dos anos 1990), durante os encontros não se podia falar de trabalho, religião, política e futebol. Segundo o mesmo, chegava-se a desmanchar a 'rodinha' se vissem alguém conversando sobre 'tais assuntos'. Sr. Toninho (como prefere ser chamado), pontua desde o início que "o Barril pode ser dividido em duas épocas: Uma antes da 'setorização"7 e eleição de reitor na Universidade e outra 'pós - setorização"8.

Historicamente, o processo de escolha de Reitores iniciou no fim da década de 1970, antes mesmo da democratização das eleições no cenário brasileiro. Na conjuntura nacional, o processo democrático nas Instituições de Ensino Superior, foi consolidado e promulgado pelo presidente Fernando Henrique Cardoso na Lei ํㅜ 9.192, de 1995 que estabelece que o Reitor e Vice-Reitor de Universidade Federal serão nomeados pelo Presidente da República e escolhidos entre professores de Carreira de Magistério Superior, dos dois níveis mais elevados ou que possuam títulos de doutor, e regulamenta o processo de consulta à

\footnotetext{
${ }^{6}$ Antônio Farias Filho, professor de Educação Física, há um ano aposentado. Foi presidente e secretário do Clube do Barril atuando por 13 anos frente ao Clube. Entrevista concedida a Josiane Eugênio Pereira e Cássia Machado. Florianópolis, 11/08/2015.

${ }^{7}$ Essa expressão foi utilizada pelo entrevistado Antônio Farias Filho em sua narrativa concedida as pesquisadoras para designar o momento vivido pelo Colégio e a Universidade, que foi a mudança da forma de escolha da gestão e a padronização dos setores e departamentos da Instituição seguindo as leis determinadas pelo Governo Federal.

${ }^{8}$ Antônio Farias Filho. Entrevista citada.
} 
comunidade universitária, e manifestação do pessoal docente (peso maior sob as demais categorias).

Com a transição do governo de Fernando Henrique Cardoso a chegada da terceirização na Universidade e no Colégio de Aplicação contribuiu para o enfraquecimento do Clube que não contou mais com os funcionários da segurança, merenda e limpeza da escola como integrantes do quadro permanente.

O concurso público para ingresso dos professores na Colégio, veio acontecer mais tarde, conforme ainda a narrativa do entrevistado Antônio Farias Filho:

Todo setor da universidade era funcionário e tinha plano de carreira, desde a segurança, desde o faxineiro, não existia terceirização. A terceirização veio na transição de governo, com o presidente Fernando Henrique [...] Ai, depois quando veio a terceirização, assim ô, a faxineira, a merendeira, passaram a não fazer mais parte do quadro[...]Antes o colégio tinha essa coisa, o segurança era da Instituição, então não tinha essa diferença.[...] Ai quando terceirizaram eles foram redistribuídos [...] Tudo do serviço de apoio, ai esse cargo foi extinto porque foi terceirizado e a universidade teve que fazer o reenquadramento.[...] É o cargo de contínuo que eles chamavam. O que aconteceu em 1987, 1988 é que foi concurso, mas até então era convite. [...] O professor entrava como substituto designado e 0 concurso acontecia dois meses, três meses depois, ai era público, e a pessoa tinha que disputar com os outros. ${ }^{9}$

Ainda segundo o entrevistado, com o passar dos anos foram-se criando 'grupos' dentro do Clube e os assuntos 'proibidos' começaram a ocupar lugares nas conversas dos encontros:

As memórias alegres ficaram no primeiro momento. Até por volta do ano de oitenta e...Vamos dizer, coloca assim, de festas boas até 1988, 1989, até 1990. Com registro com a rainha do Barril, com o que o Barril se propôs desde que foi fundado, aí depois a questão política já começou a interferir na relação entre os profissionais. ${ }^{10}$

Patrícia Belo Orofino concordou com Sr. Toninho e disse que presenciou esses dois momentos: "É, assim, as pessoas que viveram essa experiência do início do Barril e depois o 'pós', como é que é? Não havia uma discussão, o que a gente poderia mudar". ${ }^{11}$

\footnotetext{
${ }_{9}$ Antônio Farias Filho, entrevista citada.

${ }^{10}$ Antônio Farias Filho, entrevista citada.

${ }^{11}$ Patrícia Belo Orofino Pires, entrevista citada.
} 
Isso de alguma maneira, ainda segundo Antônio Farias Filho, contribuiu para o enfraquecimento do Clube do Barril:

\begin{abstract}
Não existia diferença salarial entre os funcionários, não era uma diferença muito grande, e não existia essa diferença de professor hoje, o tempo é que dava uma diferença de salário maior, essa questão formação é que é bem recente, titulação, remuneração por titulação, então tinha acumulação dos biênios, quinquênios, isso aqui é que dava uma "diferencinha" salarial. E ai o colégio começou a setorizar, ai aquela história assim, porque ele não foi na casa do 'cara', ai as festas começaram a não acontecer mais nas casas, começamos a fazer em associações no Bolanque, no SintUfsc, no HU, na Quinta dos Açores.[...] As festa começaram a fazer em local neutro, porque nas casas, eu não vou na casa do fulano porque o fulano é partidário... um era do PT, outro do PMDB, tem uma ideologia. [...] Isso já no segundo momento do Barril [...]. ${ }^{12}$
\end{abstract}

Ainda para Antônio Farias Filho no início o Clube alcançou um caráter social muito importante, eram feitas doações de brinquedos no Natal com o recurso angariado por meio das mensalidades pagas pelos sócios, os encontros eram realizados nas casas dos próprios sócios. As reuniões para marcar os encontros aconteciam nos corredores do colégio, na sala dos professores tudo era feito de uma forma comprometida, mas ainda na informalidade dialógica. ${ }^{13}$

A professora Gláucia, avalia que o enfraquecimento do Clube nesse 'segundo momento', deu-se a partir da aposentadoria dos integrantes mais antigos do Clube a pouca adesão por parte dos funcionários mais jovens, principalmente do grupo de professores substitutos. Ela cita que havia diferenças profissionais (políticas, ideológicas) mas que as mesmas não eram levadas para os encontros. Já que o grande lema do Clube era a Confraternização, a diversão, e nada além disso. ${ }^{14}$

Porém, percebe-se no que se tratou à mudança administrativa institucional, que existe quase que uma concordância unânime entre os narradores, de que as mudanças políticas, pedagógicas e institucionais das Instituições Federais no cenário brasileiro alterou de alguma maneira as formas de relações intrapessoais e de gestão nos Colégios de Aplicação. Um exemplo que traduz essa mudança e influência no cenário das relações encontramos na fala da entrevistada Patrícia Belo

\footnotetext{
${ }^{12}$ Antônio Farias Filho. Entrevista citada.

13 Antônio Farias Filho. Entrevista citada.

${ }^{14}$ Gláucia Shramm Shekel. Professora de Educação Física do Colégio de Aplicação. Atual presidente do Clube do Barril. Entrevista concedida a Josiane Eugênio Pereira e Cássia Machado. Florianópolis, 11/08/2015.
} 
Orofino ao contar que "O próprio Barril, passou a 'setorizar' também as atividades do Clube, contratando os serviços de Buffet, de festas, sonorização e os encontros passaram a atender outros objetivos que não mais aqueles genuínos estipulados em sua criação". ${ }^{15}$

Antônio Farias Filho e Patrícia Belo Orofino ${ }^{16}$, rememoram que a partir daí, as festas eram muito diferentes, pois contratavam músicos, as comidas e bebidas passaram a ser encomendadas, a divisão das tarefas não era mais como antes, de modo que, as conversas sobre o trabalho no colégio e todos 'aqueles' assuntos que até então eram evitados, foram ganhando espaço nos encontros do Clube do Barril.

Diante do contexto pedagógico e administrativo escolar, hoje o corpo docente é formado por 97 professores (entre substitutos e efetivos). O Colégio conta com um corpo de técnicos administrativos; uma equipe multidisciplinar: enfermeiros, psicólogos, assistentes sociais, dentista, nutricionista. O serviço de segurança, limpeza e alimentação é feita por uma empresa terceirizada. Destes, somente alguns (poucos) sabem ou já ouviram falar sobre o Clube do Barril, os novos funcionários do Colégio não foram fazendo mais a adesão ao Clube, por diferentes motivos conforme cita Antônio Farias Filho:

\begin{abstract}
Fizemos uma reunião quando o Barril fez 25 anos, mas já na beira mar, esqueci o nome ali, era um café colonial, onde hoje tem ali o Mc Donald. E conseguimos trazer o pessoal, uns tinham aposentado depois de 98, 98 foi uma leva onde saíram muitos professores, ai o barril perdeu força, porque os novos não foram aderindo, então aqueles que aqui estavam, com aquela ideia de escola, questão ideológica, os novos eram não alimentados por essa ideia, festa não sei o que, ai a coisa foi se perdendo e o Barril foi enfraquecendo. [...] Ainda rolou muita festa, até o ano dois mil, entramos no século agora com festa do Barril, século XXI.[...] Ele ainda existe, ele tem uma ponta, ele ainda existe! ${ }^{17}$
\end{abstract}

Formalmente e juridicamente o Clube ainda existe. Há um fundo de reserva que restou das mensalidades dos sócios depositado na conta bancária do Clube. Pretende-se segundo os entrevistados, reaver o valor depositado e realizar um reencontro com os sócios do Clube ainda este ano de 2015.

\footnotetext{
${ }^{15}$ Patrícia Orofino. Entrevista citada.

16 Antonio Farias Filho e Patrícia Belo Orofino. Entrevista citada.

17 Antônio Farias Filho. Entrevista citada.
} 


\section{CONSIDERAÇÕES FINAIS}

A expectativa com o presente texto era a de refletir sobre as memórias dos sócios do Clube do Barril, entendendo-o como parte integrante da cultura escolar, mesmo que este documento não estivesse diretamente ligado ao Colégio de Aplicação da UFSC.

Entretanto, a partir do contato com o acervo documental e especialmente com as memórias dos entrevistados sócios do Clube do Barril, cotejando com o referencial teórico e discussões trazidas foi possível perceber que esse documento se constitui como o 'guardião' de uma pequena parte da memória coletiva e individual dos funcionários do Colégio, o qual servirá como instrumento para analisar historicamente a cultura imaterial escolar da época.

O Clube do Barril tem em seu conjunto marcas da coletividade escolar. Ao 'mergulhar' no passado, soterrado nesse documento, trouxemos indícios e fragmentos que podem revelar as relações sócio afetivas, a busca de identidade social e coletiva do grupo de professores e funcionários, afinal quantas decisões podem ter sido tomadas durante esses encontros no Clube? Podemos nos questionar também se 'esses' que se reuniam tinham uma afinidade intelectual?

Apresentando as rememorações dos sujeitos que viveram os dois momentos do Clube do Barril e em resposta aos objetivos específicos estabelecidos quanto as relações que esses sujeitos vivenciaram, percebeu-se que desde a chamada democratização brasileira, na eleição para Reitor ${ }^{18}$, o cargo mais importante da Instituição desde que foi implementada à revelia da Lei, gera desconfortos e conflitos entre a comunidade da UFSC e do Colégio de Aplicação. Esse fator, foi trazido para dentro do exercício das suas profissões e demonstrado nas narrativas das memórias e experiências, pelos professores e funcionários do Colégio.

Se os encontros dos profissionais eram considerados mais prazerosos, se havia mais união e amizade especialmente no primeiro momento de existência do

18 Conforme já exposto existe um processo de escolha direta à comunidade na forma de eleição em âmbito paritário e aberto. Informação obtido no site institucional da Universidade Federal de Santa Catarina. 
Clube, a tensão ideológica foi apontada pelos entrevistados como um problema que surgiu no decorrer dos anos.

Alguns dos narradores desse estudo, ao falar do Clube, lembram o exemplo de união e de coleguismo entre os profissionais, mas de alguma forma, todos os entrevistados deixaram transparecer que houveram mudanças de comportamento dos sócios ao longo do tempo. Escolhemos uma fala que pode ilustrar essa análise: "Se existiam tensões dentro do Clube não percebi! Mas se tinham ocorrido algumas tensões, considero natural em qualquer grupo tal ocorrência". ${ }^{19}$

Percebe-se que quando o sujeito conta a sua história, sistematiza as ideias e reconstrói experiências, ele abre assim, espaços para uma autoavaliação e busca pela compreensão da sua própria prática no contexto vivido.

Dizer que o Clube do Barril ainda existe, significa apostar na força da memória social e coletiva, tão abalada pelas ruínas históricas decorrentes do 'progresso'. O 'progresso' transforma a sociedade e modifica também as relações pessoais, corrompe com a coletividade e com a experiência cotidiana, por isso é importante trazer fragmentos do passado. Desta forma, é inevitável não lembrar da alegoria do anjo da história de Walter Benjamin, um anjo melancólico, ante os detritos que se avultam abaixo dos seus olhos sem que nada se possa fazer a respeito, por causa da 'tempestade' chamada progresso (o futuro, o vir a ser). No entanto, é preciso que o anjo acorde os 'mortos' trazendo à tona o passado ao vivêlo no presente ciente de que o que foi não voltará mais, embora as esperanças soterradas possam vir à luz no agora.

Não obstante, é possível notar o quanto a história oral possibilita ao pesquisador desvelar outros modos de convivência coletiva, e sendo uma produção intelectual orientada para a produção de testemunhos históricos, contribui para evitar o esquecimento e para registrar múltiplas visões sobre o que passou.

A análise do documento não encerra nesse artigo. Fica o convite para refletir acerca dos futuros desdobramentos e sobre os critérios adotados pelas instituições escolares a respeito dos documentos a serem salvaguardados. Este estudo é um convite para refletir sobre qual a razão que motivou os funcionários a

\footnotetext{
19 Maria Elza. Professora-orientadora educacional. Entrevista concedida a Cássia Machado. Florianópolis12/08/2015.
} 
guardarem toda a documentação chamado Clube do Barril na escola, mesmo este não 'pertencendo legalmente' as questões didáticas, pedagógicas e institucionais do Colégio.

Por fim, o presente estudo não teve o propósito de encerrar o debate, mas sim de abrir novas possibilidades de investigação e escavações norteadas pela perspectiva da cultura escolar. Reconhecemos que este ensaio contém limitações e que exigirá entrelaçamentos com futuras pesquisas, desta forma, sugerimos que o referido documento seja visto a 'contrapelo' da história, ou seja, aprofundado com estudos de mais sócios e dos não sócios revelados/as pelos narradores do Clube do Barril.

\section{REFERÊNCIAS}

ANDRADE, Maria Clarete Borges de. Cultura Escolar no Ginásio de Aplicação: Universidade Federal de Santa Catarina na década de 1960. Dissertação de Mestrado. Universidade Federal de Santa Catarina, Florianópolis,2009.

BENJAMIN, Walter. O anjo da História. Edição e tradução João Barrento. Belo Horizonte: Autêntica, 2012.

BENJAMIN, W. Obras escolhidas: Rua de mão única. 2 ed. São Paulo: Brasiliense,1987.

BOSI, Ecléa. Memória e sociedade - lembranças de velhos. 3ed. São Paulo: Cia das Letras, 1994. 484p.

FREITAS, Sônia Maria de. História Oral: possibilidades e procedimentos. $2^{\mathrm{a}}$ ed. São Paulo. Associação Editorial Humanitas. 2006.

FREIRE, Paulo. Pedagogia da autonomia: saberes necessários à prática educativa. 41. ed Rio de Janeiro: Paz e Terra, 2010.

GAGNEBIN, Jeanne Marie. Limiar, Aura e Rememoração: Ensaios Sobre Walter Benjamin. São Paulo: Ed. 34, 2014.

. História e Narração em W. Benjamin. Campinas, SP: São Paulo: Perspectiva / FAPESP / UNICAMP, 1999

LAROSA, Jorge. Notas sobre narrativa e identidade. Conferência proferida no $1^{\circ}$ Congresso Internacional sobre Pesquisa (Auto) Biográfica. Rev. PUCRS, Educação, 
Porto Alegre, v. 34, n. 2, p. 147-156, maio/ago. 2011. Disponível em:<revistaseletronicas.pucrs.br>.Acesso em: 20 junho 2015.

OLIVEIRA, Anelise Martinelli Borges de. Práticas de leitura e história oral: Condicionantes para se pensar o Colégio Tiradentes. Revista Encontro de Pesquisa em Educação. Uberaba, v. 1, n.1, 2013, p. 55-67.

PAIM, Elison Antonio. Memórias e experiências do fazer-se professor(a). Jundiaí: Paco Editorial, 2012.

PESAVENTO, Sandra J. História e História Cultural. Belo Horizonte: Autêntica, 2004.

PEREIRA, Josiane Eugênio. História, memória e educação: Infâncias de pessoas com deficiência mental/intelectual (Maracajá-SC,1995-1970). Dissertação de Mestrado. Universidade do Extremo Sul Catarinense - UNESC, Criciúma,2013.

THOMPSON, Paul. História Oral e Contemporaneidade. Trad. Andréa Zhouri e Lígia Maria Leite Pereira. Revista História Oral. São Paulo, n. 5, jul. 2002, p. 8-29

\section{FONTES ORAIS}

Antônio Farias Filho. Entrevista concedida a Josiane Eugênio Pereira e Cássia Machado. Florianópolis, 11/08/2015.

Gláucia Shramm Shekel. Entrevista concedida a Josiane Eugênio Pereira e Cássia Machado. Florianópolis, 11/08/2015.

Maria Elza. Entrevista concedida a Cássia Machado. Florianópolis 12/08/2015.

Patrícia Belo Orofino Pires. Entrevista concedida a Josiane Eugênio Pereira e Cássia Machado. Florianópolis.11/08/2015. 